\title{
Coordinates of a New Romanian Regional Policy - Identifying the Development Poles. A Case Study
}

\author{
Adriana DAVIDESCU, Vasile Alecsandru STRAT \\ Bucharest University of Economic Studies, Department of Statistics and Econometrics \\ adrianaalexandru@yahoo.com, vasile.strat@csie.ase.ro
}

The sustainable regional development is a crucial topic at the level of the EU nowadays. Therefore, the regional policies of the member states should be constructed in such a fashion, that they comply with the general European framework and maximize the potential of reaching the European goals. Following the general trend, Romania finds itself today in a complex project of rethinking its regional approach. The approach proposed in this paper will try, using statistical methods and aggregate data available in the Tempo database, to identify those counties that have the necessary characteristics in order to be taken in consideration when choosing the core county of each new region.

Keywords: Development Region, Sustainable Development, Principal Components Analysis, Development Pole

\section{1} Introduction

When talking about globalization [1], the concept of sustainable development appears frequently as one of the fundamental coordinates of the entire concept. Moreover, of significant importance is the fact that when talking about sustainable development a wide range of aspects are embodied, as [17] described. In the last decades another concept, namely the regional development, has emerged and has gained a significant importance in the general framework (The entire European Union is constructed on the concept of regional development). If sustainable development is, in general, related to resource management, regional development is mostly concerned with the reduction of the disparities between regions. Nevertheless, the two concepts have a common point, and that is: environmental protection [15] through the responsible use of resources. Thereby, we support the idea that the main purpose of the newly developed concept of sustainable regional development can be defined as the pursuit of the long-term economic growth, when regarding the environmental welfare as a crucial aspect.

The main purpose of the present paper is to identify the principal regional poles of sustainable development for the case of Romania (using multidimensional analysis techniques and aggregate data available) by high- lighting the counties that have the necessary characteristics in order to be taken into consideration when choosing the core county of each new region.

In the literature review section, we try to provide a brief description of the current level of research concerning the topic of regional development at national and international level, noting the main directions pursued by researchers. In the methodology section we focus our attention on presenting the main goal of the research, the analysis methods implied by the present research and finally we describe the data that were used in the paper. The section empirical results summarizes the main empirical results of the paper presenting the counties that have the greatest probability of being selected as regional development poles in a new hypothetical reorganization of the development regions of Romania. In the final section we summarize the main results obtained and we suggest some further research directions that would increase the value of the results and would provide them with a clear practical applicability.

\section{Literature Review}

The concept of regional sustainable development is well reflected in the literature, where researchers, following different study directions, have created important and valua- 
ble knowledge through a large variety of research papers. One of the basic goals of the regional sustainable development is constructing a better economic environment that will lead into an increase in the standard of living for the regions' inhabitants. In order to be able to do so, one of the best methods that can be chosen by the regional policy makers represents the construction of efficient policies that can attract foreign direct investments in their region. This aspect is largely described by the literature, where the main direction followed by the researchers is exactly the analysis of foreign direct investments at regional level (an analysis of the characteristics that make a region appealing to foreign investors).

Porter in [22] highlights the fact that the foreign direct investments are attracted in specific areas by some regional factors and therefore we can suggest that foreign direct investments might be seen as one of the driving forces of the regional development. Accordingly, [9], [23], [14], reveal significant evidence, showing that market size is one of the most important aspects that foreign investors search for in a specific region. Other relevant regional determinants of foreign direct investments, identified by the literature are: labour market [9] and [19], infrastructure [28], [21], [4] and research and development level [6], [7] and [8].

Due to the fact that increasing the standard of living for the regions' inhabitants is one of the main goals of a regional sustainable development policy, identifying and analyzing the regional disparities and differences that are very frequent today in almost every state, is another important direction followed by a large variety of studies. Papers concerning this topic analyze disparities and differences among regions with respect to a great range of fields, like: infrastructure related aspects [12], tourism related aspects [29], [26], labour market related aspects [5], [27] and many other socio-economic aspects [25]. In addition to the analysis of these disparities among European regions, studies concerned with this topic, also provide some solutions, that might be regarded as components of larger policies developed by the decision makers in order to reduce the identified disparities [10], [13] and [20].

Also very important to mention in this context is the cohesion coordinate of the European Union policies, which is mostly concerned with reducing the regional disparities [2]. Consequently, constructing viable regional entities and adopting a coherent regional policy is, in the present reality, the only solution that can be adopted by the Romanian authorities in order to reduce the gap concerning the standard of living, between the Romanian citizens and other European citizens. Thus, the new regional organization of the territory is regarded in Romania as a key factor that can drive the future development of the country and it is strongly argued that this new administrative organization is necessary in order to develop the appropriate tools (for the Romanian authorities) for achieving a better absorption of the European funds (for the period 2014 - 2020).

After the fall of communism, the movement towards the Western European space was decided to be one of the main goals of the entire Romanian society. Thereby, shifting the administrative policy from the highly centralized form, distinctive to the former communist era, to the regional based one, distinctive for the European Union, became one of the most important coordinates (a long term process) of the national policies. A very important step was made in 1998, when the decision makers constructed eight development regions (each region contains more counties), who serve as NUTS II units (these units do not have an administrative role yet). After that significant moment the entire process has continued in a much slower rhythm, with no further notable milestones. The process seemed to enter a new stage, due to the fact that the last three years have been the scene of some important debate (at political level) about the construction of the general framework required for constructing fully functional development regions. The scenarios, which are still under debate for the moment, involve reorganization of the existing eight 
development regions and also of the capital cities for each of the newly created regions.

When talking about empirical studies, the Romanian literature dealing with the study of regional aspects is rather poor, showing a significant increase in the last years. One important topic that is covered by the existing papers is the existence of regional disparities among the eight Romanian development regions. Conducting a thorough analysis of the regional disparities [3], [16] and constructing a SWOT profile of each region should be considered in every scenario as the basic step for any future viable reorganization process. Consistent with the international literature another direction followed by the Romanian researchers consists in analyzing the attractiveness of the Romanian development regions when talking about the location process of foreign direct investments [11]. Another important aspect that might throw some light over the development level of the Romanian regions, analyzed in the broader European context is the fact that according to Eurostat data (2012) three of the Romanian regions (South-East, North-East and South-West) have less than $1 \%$ of the total number of employees hired in high technology sectors in 2011. Also noteworthy is the study published in 2010 by Roman M., where she analyses the regional efficiency of the knowledge economy in the newly member states of the EU: Romania and Bulgaria

\section{Methodology - Research Goal and Anal- ysis Methods}

The central objective of the paper is to highlight the main poles of regional sustainable development for the case of Romania using principal component analysis (PCA) and a clustering technique. Therefore, the research conducted in this paper will use the principal component analysis (PCA) in order to identify the most important factors from the perspective of regional development. Using the factors constructed in the principal component analysis (PCA) phase as input variables, in the second part of the paper a clustering algorithm will be used in order to identify the counties that might be regarded as regional development poles in a future reorganization process.

The analysis is based on the 40 Romanian counties (Bucharest and Ilfov county were excluded from our analysis since they are in all scenarios presented as a single and different region; also, Bucharest is an outlier regarding all variables included in our analysis) using the most relevant regional indicators available for the year 2011. The main source of data used for all these indicators is the Tempo database constructed by the National Institute of Statistics. The variables included in the analysis conducted in this research paper are: activity rate, unemployment rate, number of graduates, number of libraries, life expectancy, number of emigrants, respectively number of immigrants, cultivated area, average production by hectare, number of active enterprises, number of postal units, tourist arrivals, number of households connected to the public water supply, number of municipalities, number of cities, built area.

\section{Empirical Results}

The main objective of this section is to identify important synthetic indicators of regional development in Romania using the principal component analysis technique and to highlight the main regional poles of sustainable development using aggregate data at the level of the year 2011.

Information on quality adjustment is expressed using the variance explained with the help of the eigenvalues (presented in Table 1) and the matrix of correlations. The table presents the variance explained by the initial solution (components), the extracted components and also the rotated components. Therefore, the analysis of the quality of the cloud of points adjustment (in our case the counties) is performed using the eigenvalues. The first five principal components from the extracted solution are explaining nearly $76.16 \%$ of the variability in the original sixteen variables and they are the only ones with eigenvalues higher than 1 . Regarding the entire process, step by step, we notice that adjusting the points' cloud by a single factorial axis (accepting only the first synthetic indica- 
tor), explains $39.27 \%$ of total variance; then, adjusting the points' cloud by the first two factorial axes (accepting two synthetic indicators) we recover an additional $12.51 \%$ of the total variance (a total of $51.79 \%$ of the initial variance). If we use the first three facto- rial axes (three synthetic indicators) we explain $61.56 \%$ from the total variance, while when using all first five synthetic indicators we recover about $76.16 \%$ of the total variance.

Table 1.The component Eigenvalues

\begin{tabular}{|c|c|c|c|c|c|c|c|c|c|}
\hline \multirow[b]{2}{*}{ Comnonent } & \multicolumn{3}{|c|}{ Initial Eigenvalues } & \multicolumn{3}{|c|}{ Extraction Sums of Squared Loadings } & \multicolumn{3}{|c|}{ Rotation Sums of Squared Loadings } \\
\hline & Total & $\%$ of Variance & Cumulative $\%$ & Total & $\%$ of Variance & Cumulative $\%$ & Total & $\%$ of Variance & Cumulative $\%$ \\
\hline 1 & 6,284 & 39,276 & 39,276 & 6,284 & 39,276 & 39,276 & 4,850 & 30,312 & 30,312 \\
\hline 2 & 2,003 & 12,516 & 51,793 & 2,003 & 12,516 & 51,793 & 2,842 & 17,762 & 48,073 \\
\hline 3 & 1,564 & 9,775 & 61,568 & 1,564 & 9,775 & 61,568 & 1,521 & 9,504 & 57,577 \\
\hline 4 & 1,292 & 8,075 & 69,642 & 1,292 & 8,075 & 69,642 & 1,488 & 9,299 & 66,876 \\
\hline 5 & 1,043 & 6,518 & 76,160 & 1,043 & 6,518 & 76,160 & 1,485 & 9,284 & 76,160 \\
\hline 6 & .842 & 5,263 & 81,424 & & & & & & \\
\hline 7 & 816 & 5,098 & 86,521 & & & & & & \\
\hline 8 & .711 & 4,446 & 90,968 & & & & & & \\
\hline 9 & .474 & 2,964 & 93,932 & & & & & & \\
\hline 10 &, 315 & 1,970 & 95,901 & & & & & & \\
\hline 11 & .210 & 1,315 & 97,216 & & & & & & \\
\hline 12 & .147 &, 920 & 98,137 & & & & & & \\
\hline 13 & .131 & 819 & 98,956 & & & & & & \\
\hline 14 &, 081 & .505 & 99,461 & & & & & & \\
\hline 15 &, 062 &, 388 & 99,849 & & & & & & \\
\hline 16 &, 024 & 151 & 100,000 & & & & & & \\
\hline
\end{tabular}

In order to explain the significance of the principal components obtained through our analysis, one has to analyze the correlation coefficients calculated between the five main components (the extracted components) and the original indicators. By applying such a methodology the process of explaining the principal components becomes relatively simple. As a first step one has to use a rotation technique in order to obtain components on orthogonal axes. The most common rotation technique used for this purpose is the "Varimax" method. The second step involves finding which initial variables are most correlated with each principal component. Afterwards, each of the principal components needs to be renamed so that it can be regarded as a new dimension, a new class that needs to include the significance of all the initial variables. Therefore each component can be "explained" by the initial variables for which the correlation coefficients have the highest values (the results are presented in Table no. 2). Following this methodology we can consider the first component as being explained by the number of graduates, number of libraries, number of emigrants, number of active enterprises, number of postal units, number of households connected to public water supply and number of municipalities. This first component explains $39.76 \%$ of the initial variance and therefore can be linked with almost half of the initial variables. Thus, we can consider this component as a measure of the general potential of the economic environment.

The second component is most correlated with the unemployment rate (negative correlation), the tourists' arrivals, the number of cities and the total urban area (surface). Considering these correlations we should regard this factor as an indicator of the importance of the urban environment in the county.

The third component can be explained in the terms of life expectancy (this factor is the only one that correlates with only one of the initial variables). The fourth component can be defined as a measurement indicator of the activity rate because it is highly correlated with the activity rate and negatively with the number of immigrants. Finally the fifth component can be easily explained in terms of agricultural activity because it is highly correlated with the cultivated area and with the 
average productivity by hectare.

Table 2.The Rotated Component Matrix

\begin{tabular}{|c|c|c|c|c|c|}
\hline & \multicolumn{5}{|c|}{ Component } \\
\hline Activity rate & Fact1 & Fact2 & Fact3 & Fact4 & Fact5 \\
\hline Unemployment rate & .200 & .096 & .022 & .832 & -.031 \\
Number of graduates & -.142 & -.762 & .114 & .003 & -.195 \\
Number of libraries & .862 & .355 & -.140 & -.129 & .107 \\
Life expectancy & .679 & .068 & -.614 & -.017 & .011 \\
Number of emigrants & -.058 & -.083 & .904 & .086 & .116 \\
Number of immigrants & .704 & .367 & .016 & -.339 & -.027 \\
Cultivated area & .578 & -.086 & -.257 & -.647 & -.103 \\
Average productivity by hectare & .143 & -.196 & -.002 & -.150 & .755 \\
Number of active enterprises & -.052 & .202 & .146 & .177 & .674 \\
Number of postal units & .815 & .429 & -.030 & .109 & .230 \\
Tourists' arrivals & .791 & .054 & -.181 & .293 & -.132 \\
Number of households connected to & .489 & .647 & .241 & -.015 & .183 \\
the public water supply & .754 & .426 & -.033 & .023 & .220 \\
Number of municipalities & .615 & -.010 & .319 & .246 & -.398 \\
Number of cities & .113 & .789 & -.055 & .134 & -.188 \\
Built area & .492 & .696 & -.097 & .090 & -.199 \\
\hline Extraction Method: Principal Component & Analysis. \\
Rotation Method: Varimax with Kaiser Normalization. & & \\
a Rotation converged in 8 iterations. & & & \\
\hline
\end{tabular}

In order to identify the counties that are most suited to be regarded as development poles (from the 40 counties) we have conducted ten analyses using for each of them a combination of two of the main five principal components. Our approach was constructed following the hypothesis that for each of the performed analyses the counties that have the greatest probability of being selected as development poles are the counties that have a score higher than the average for both PCs entered in the analyze. For each of the ten possible combinations the poles are easily identifiable on the Scatter Plot (Figure 1, Figure 2, Figure 3, Figure 4 and Figure 5).
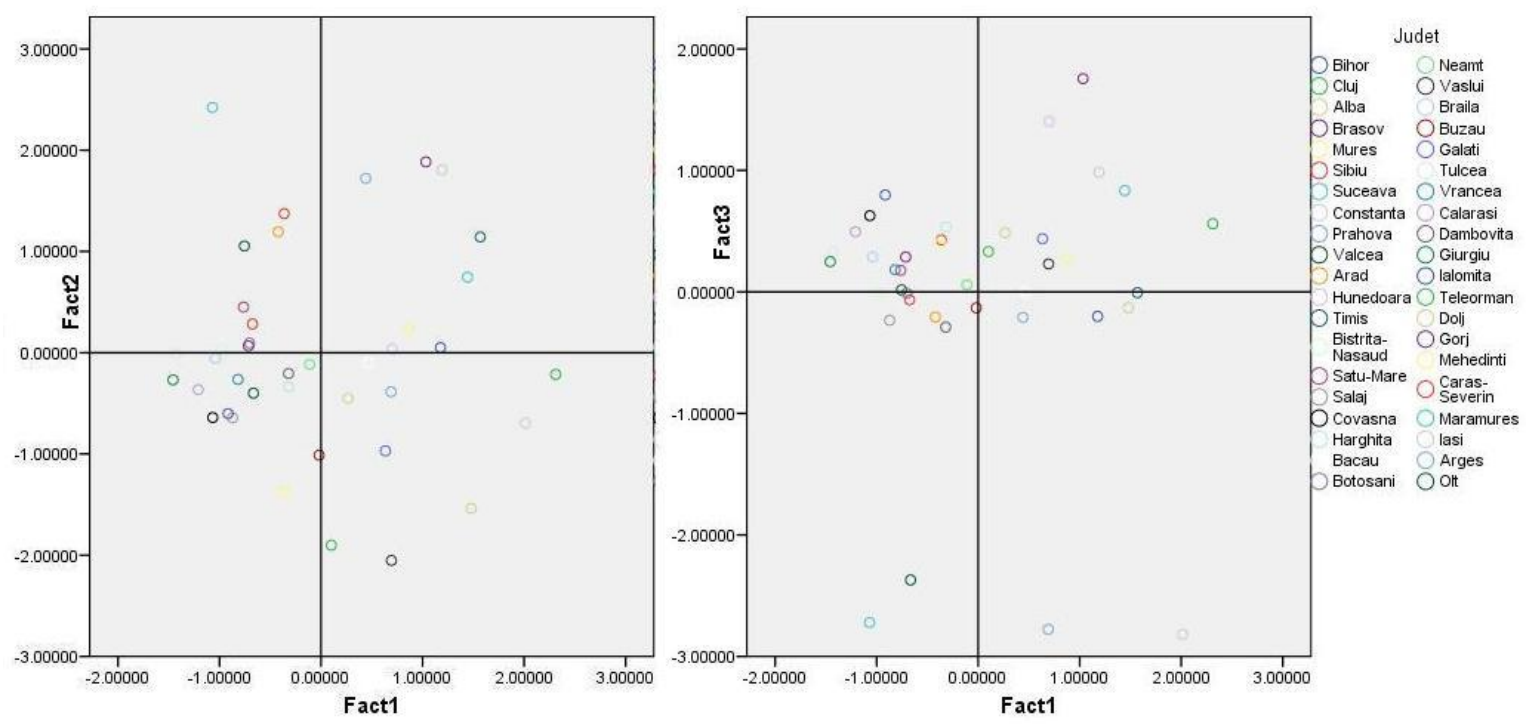

Fig. 1. County component scores for the first and combinations 
For the first combination of components (the first factor and the second factor) the counties that are more likely to be identified as regional development poles are: Bihor, Brasov, Mures, Suceava, Constanta, Prahova, Hunedoara and Timis. These eight counties have above average performances both for general potential of the economical environment and for the importance of the urban environment in the county. As it is visible from the chart these eight counties might be further classified into three new clusters.
When analysing the output of the second combination of factors we are able to identify eleven counties that might be taken into account when speaking about regional development poles. These 11 counties that perform above average for both the general potential of the economical environment and for the life expectancy are: Cluj, Alba, Brasov, Mures, Suceava, Constanta, Hunedoara, Bacau, Vaslui, Galati and Teleorman. These eleven counties might be clustered into five new classes if the analysis is performed further.
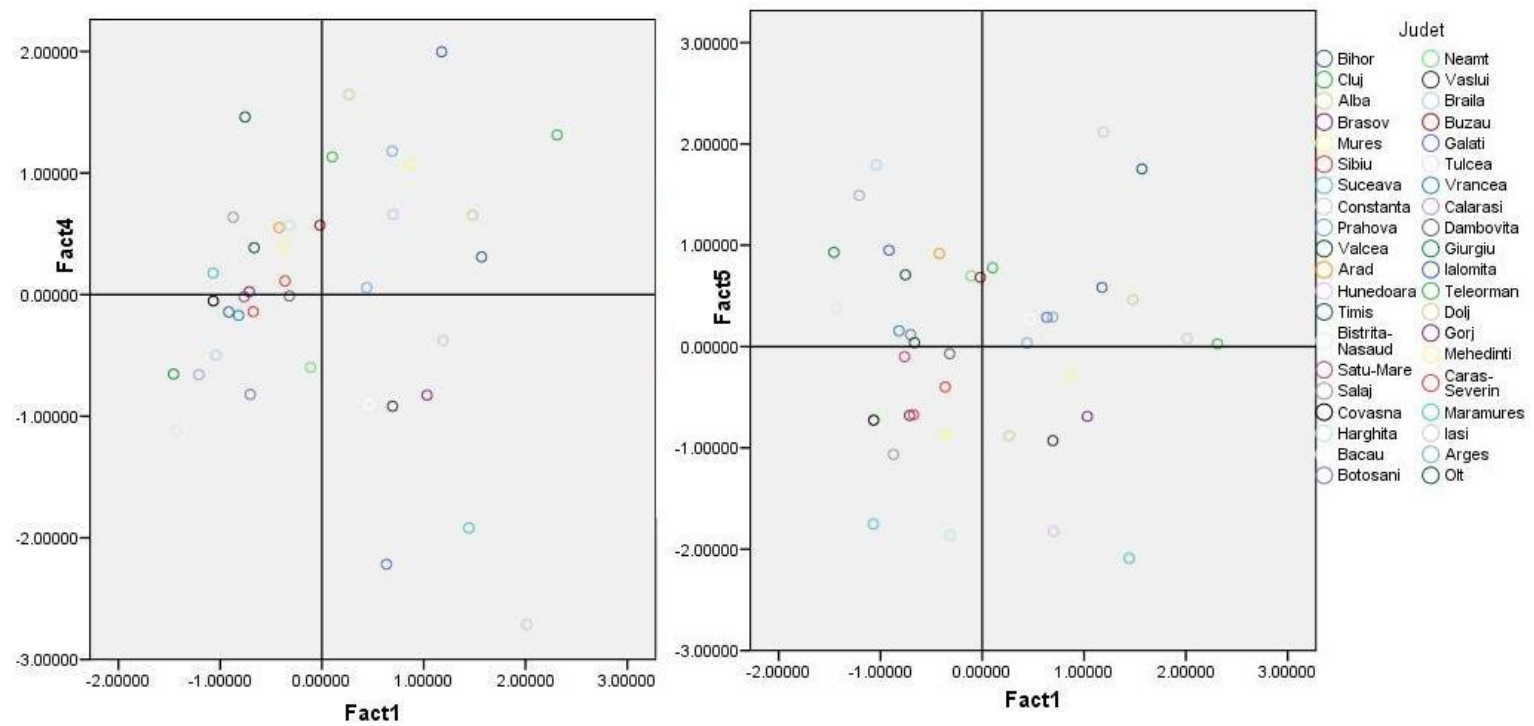

Fig. 2. County component scores for the third and fourth combinations

For the third combination of the PCA factors, the counties that have the greatest propensity to be identified as regional development poles are as follows: Bihor, Cluj, Alba, Mures, Prahova, Hunedoara, Timis, Teleorman, Dolj and Arges. These 10 counties have above average performances both for general potential of the economical environment and for the activity rate. As it is visible from the chart these ten counties are scattered and a further classification might not be a very reliable one.
Analyzing the fourth combination we are able to identify eleven counties that might be taken into account when discussing the regional development poles aspects. These eleven counties that perform above average for both the general potential of the economical environment and for the agricultural activity are: Bihor, Cluj, Constanta, Prahova, Timis, Bacau, Galati, Teleorman, Dolj, Iasi and Arges. If the analysis goes further these eleven counties might be clustered into five new classes. 

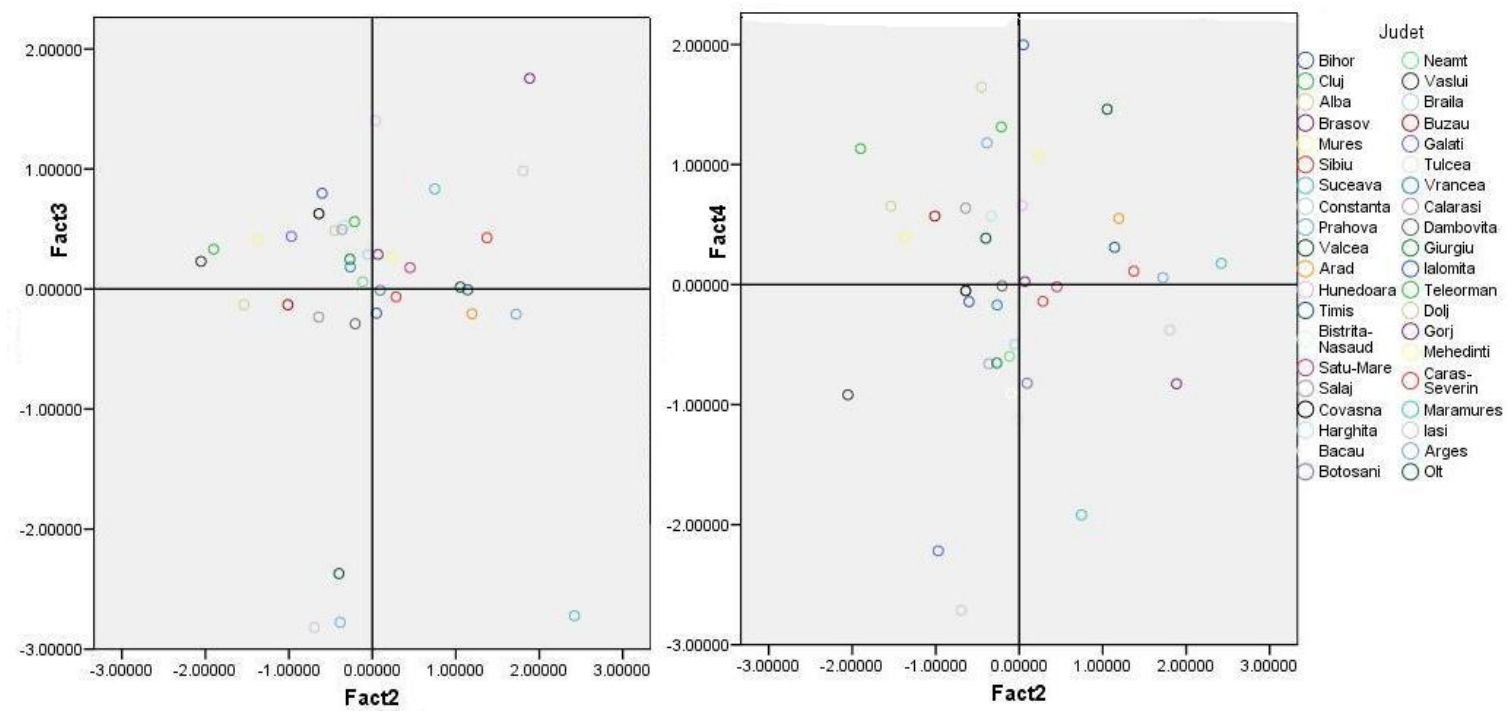

Fig. 3. County component scores for the fifth and sixth combinations

When discussing the fifth combination of the factors resulted from the principal components analysis we are able to identify nine counties that might be taken into account when discussing aspects related with regional development poles. These 9 counties that perform above average for both the importance of the urban environment in the county and for life expectancy are: Brasov, Mures, Sibiu, Suceava, Constanta, Valcea, Hunedoara, Satu-Mare and Gorj. Five of these counties might be further grouped into two clusters. The remaining four are scattered making therefore useless a further classification. For the sixth combination of the factors the counties that have the greatest probability to be identified as regional development poles are: Bihor, Mures, Sibiu, Prahova, Arad, Valcea, Hunedoara, Timis, Gorj si Maramures. These 10 counties have above average performances both for the importance of the urban environment in the county and for the activity rate. As it is visible from the chart, seven of these counties can be further grouped into two more clusters.
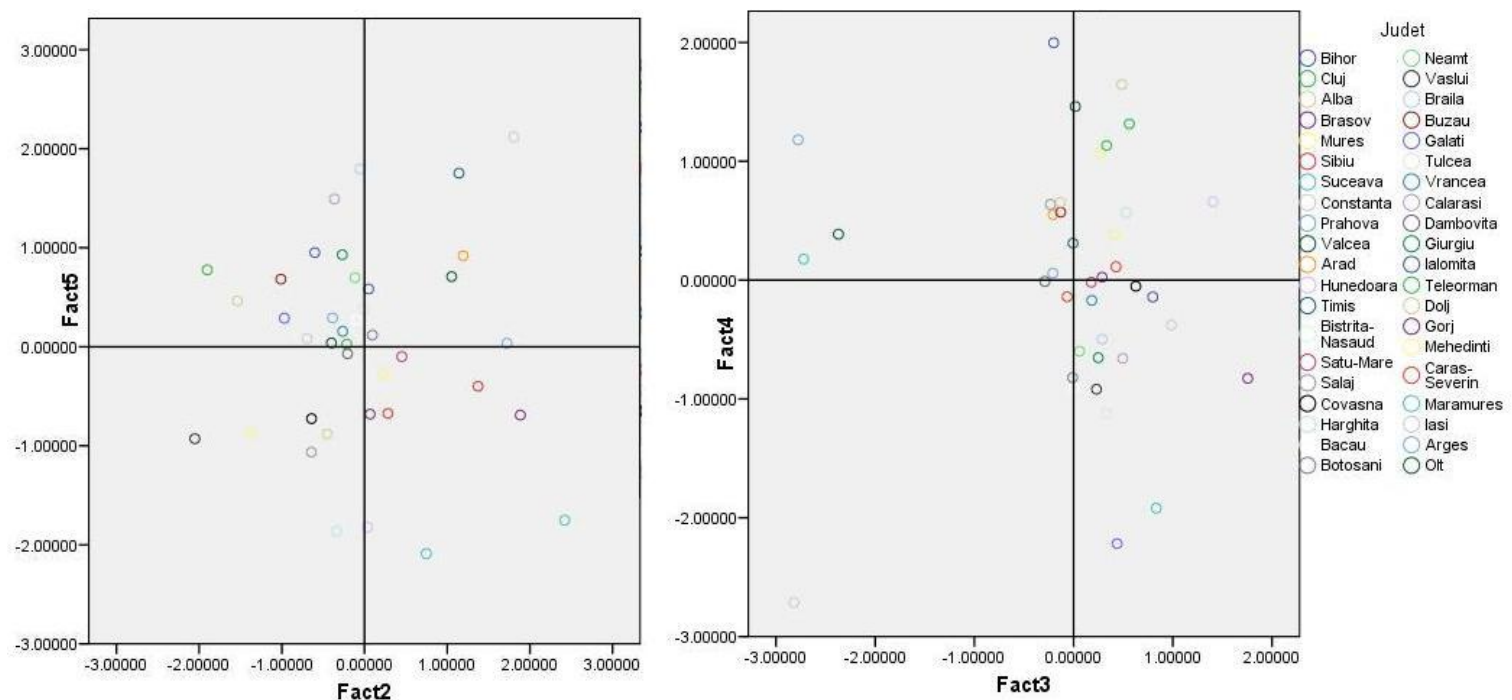

Fig. 4. County component scores for the seventh and eight combinations

For the seventh combination of components, the counties those are more likely to be considered as regional development poles in a reorganization scenario, are: Bihor, Constanta, Prahova, Valcea, Arad, Timis and Botosani. These seven counties have above 
average performances both for the importance of the urban environment in the county and for the agricultural activity. As it is visible from the chart these seven counties could be further classified into four new clusters.

Using the combination number eight we are able to identify 10 counties that might be taken into account when discussing the re- gional development poles' aspects. These 10 counties that perform above average for both the life expectancy and for the activity are as follows: Cluj, Alba, Mures, Sibiu, Valcea, Hunedoara, Harghita, Teleorman, Gorj and Mehedinti. According to the chart, a further classification of these 10 counties might be performed in three new clusters.
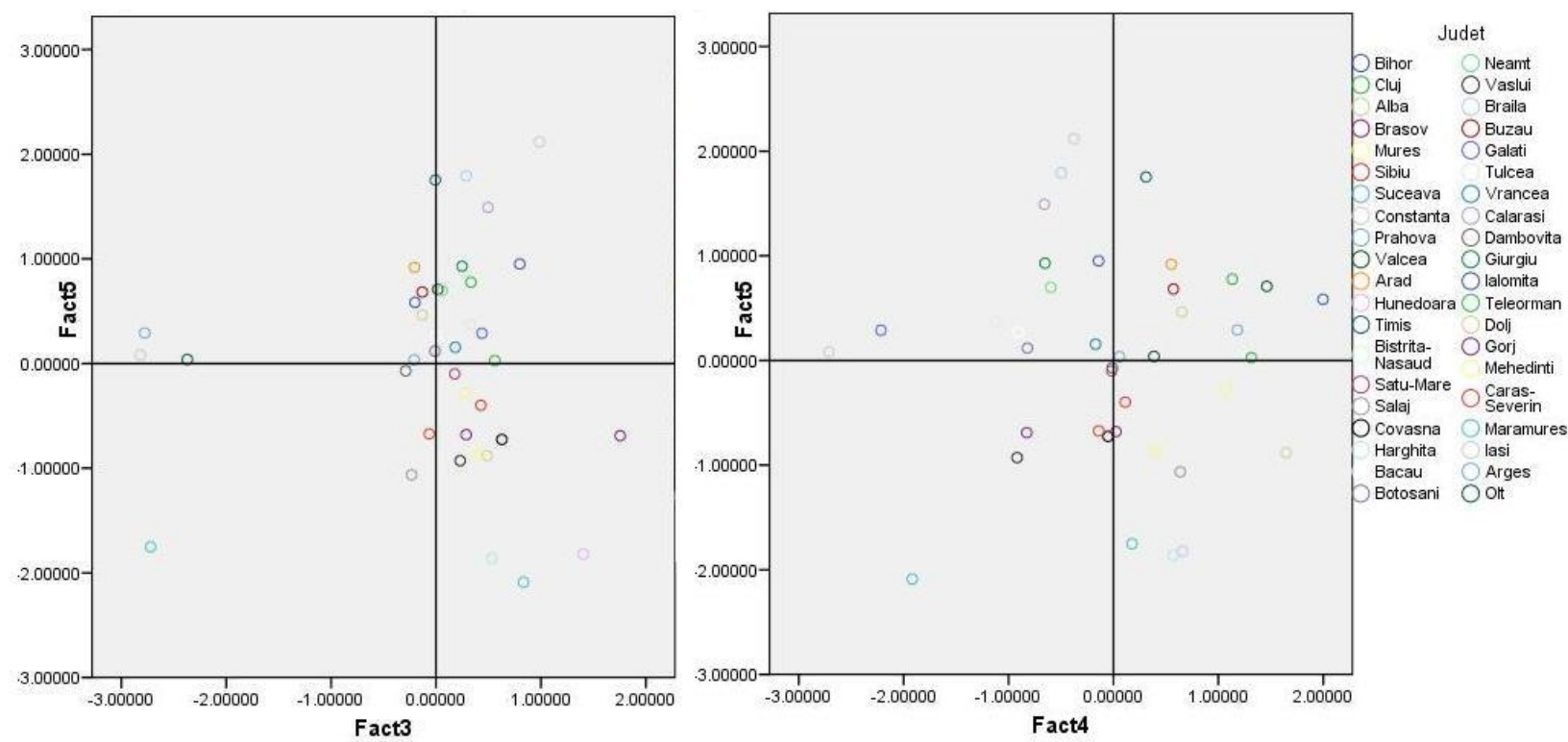

Fig. 5. County component scores for the ninth and tenth combinations

For the ninth combination of the principal components, the counties that are more probably to be selected as regional development poles are: Cluj, Constanta, Valcea, Bacau, Neamt, Braila, Galati, Tulcea, Vrancea, Calarasi, Giurgiu, Ialomita and Teleorman. These thirteen counties have above average performances both for the life expectancy and for the agricultural activity, and as it is visible from the chart they could be further classified into four new clusters.

Analysing the last combination of factors we are able to identify eleven counties that might be taken into account when analyzing the opportunity of reshaping the administrative or- ganization of the country around new regional development poles. These eleven counties that perform above average for both the activity rate and for agricultural activity are: Bihor, Cluj, Prahova, Valcea, Arad, Timis, Buzau, Teleorman, Dolj, Arges and Olt. According to the chart, if a further classification is desired, the eleven counties might be grouped as follows: four new clusters and two isolated counties.

Summarizing the results of the analyzed cross-factor combinations, in the next table we will list, for each of the counties, the number of times when the county performed above average for both components.

Table 3. Totals for all countries

\begin{tabular}{|c|l|c|c|l|c|}
\hline No. & County & Total & No. & County & Total \\
\hline $\mathbf{1}$ & Bihor & 6 & $\mathbf{2 1}$ & Neamt & 1 \\
\hline $\mathbf{2}$ & Cluj & 6 & $\mathbf{2 2}$ & Vaslui & 1 \\
\hline $\mathbf{3}$ & Alba & 3 & $\mathbf{2 3}$ & Braila & 1 \\
\hline $\mathbf{4}$ & Brasov & 3 & $\mathbf{2 4}$ & Buzau & 1 \\
\hline
\end{tabular}




\begin{tabular}{|c|l|c|c|l|l|}
$\mathbf{5}$ & Mures & 6 & $\mathbf{2 5}$ & Galati & 3 \\
\hline $\mathbf{6}$ & Sibiu & $\mathbf{3}$ & $\mathbf{2 6}$ & Tulcea & 1 \\
\hline $\mathbf{7}$ & Suceava & 3 & $\mathbf{2 7}$ & Vrancea & 1 \\
\hline $\mathbf{8}$ & Constanta & 6 & $\mathbf{2 8}$ & Calarasi & 1 \\
\hline $\mathbf{9}$ & Prahova & 6 & $\mathbf{2 9}$ & Dambovita & 0 \\
\hline $\mathbf{1 0}$ & Valcea & 6 & $\mathbf{3 0}$ & Giurgiu & 1 \\
\hline $\mathbf{1 1}$ & Arad & 3 & $\mathbf{3 1}$ & lalomita & 1 \\
\hline $\mathbf{1 2}$ & Hunedoara & 6 & $\mathbf{3 2}$ & Teleorman & 6 \\
\hline $\mathbf{1 3}$ & Timis & 6 & $\mathbf{3 3}$ & Dolj & 3 \\
\hline $\mathbf{1 4}$ & Bistrita-Nasaud & 0 & $\mathbf{3 4}$ & Gorj & 3 \\
\hline $\mathbf{1 5}$ & Satu-Mare & 1 & $\mathbf{3 5}$ & Mehedinti & 1 \\
\hline $\mathbf{1 6}$ & Salaj & 0 & $\mathbf{3 6}$ & Caras-Severin & 0 \\
\hline $\mathbf{1 7}$ & Covasna & 0 & $\mathbf{3 7}$ & Maramures & 1 \\
\hline $\mathbf{1 8}$ & Harghita & 1 & $\mathbf{3 8}$ & lasi & 1 \\
\hline $\mathbf{1 9}$ & Bacau & 3 & $\mathbf{3 9}$ & Arges & 3 \\
\hline $\mathbf{2 0}$ & Botosani & 1 & $\mathbf{4 0}$ & Olt & 1 \\
\hline
\end{tabular}

Therefore counties that have the greatest probability of being selected as regional development poles (they have a score higher that the average for both components in six of the performed analyses) are: Bihor, Cluj, Mures, Hunedoara, Constanta, Prahova, Valcea, Teleorman and Timis. Counties that have a score higher that the average for both components in three of the conducted anal- yses are: Alba, Brasov, Sibiu, Suceava, Arad, Galati, Dolj, Gorj Bacau and Arges. The other counties are divided into two more clusters, as follows: counties that performed better that average for both components of a combination and counties that have never performed better that the average for both components (Salaj, Bistrita-Nasaud, CarasSeverin, Covasna and Dambovita).

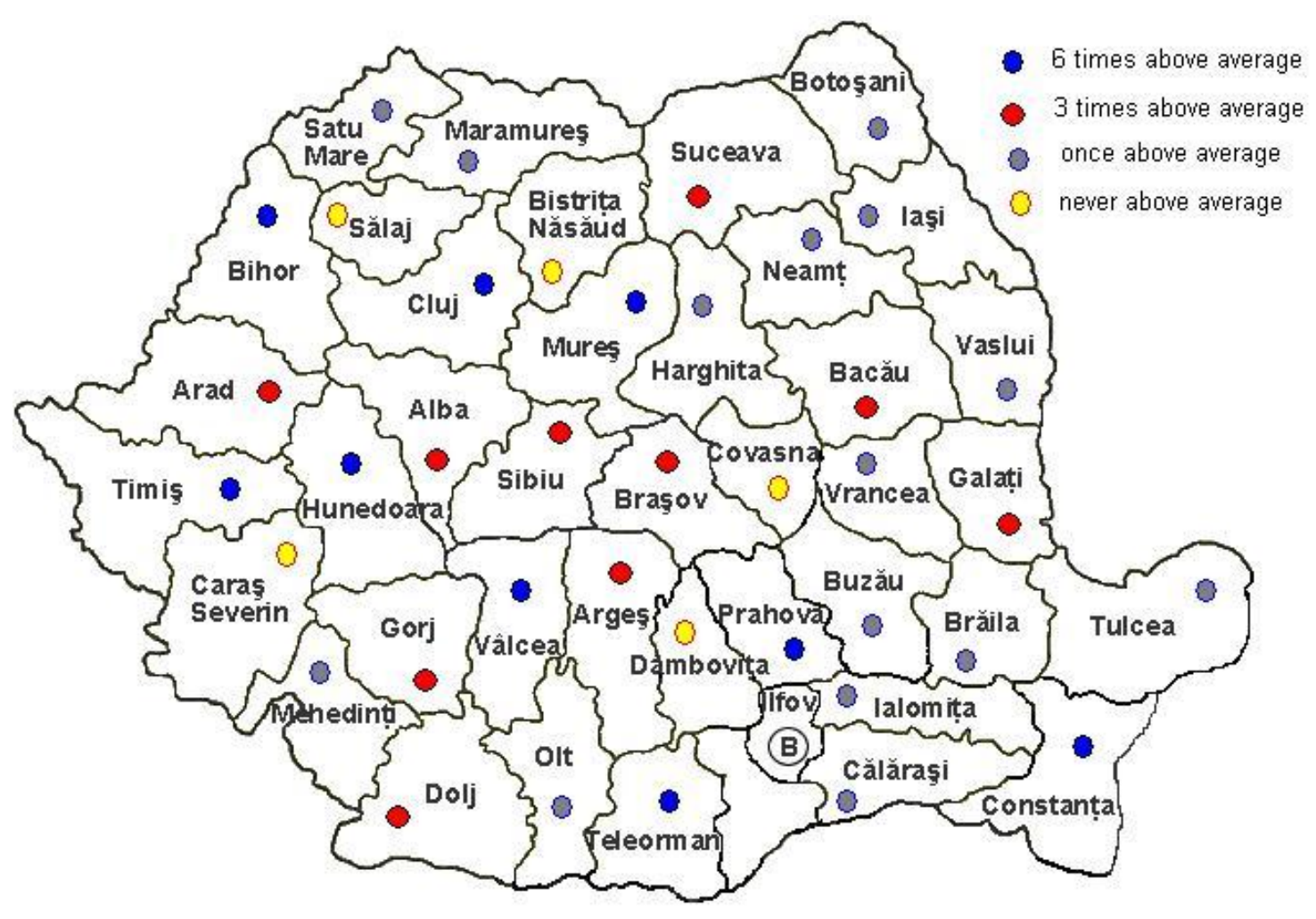

Fig. 6. The Romanian regional development poles 


\section{Conclusions}

The main purpose of this paper was to identify the most important regional poles of sustainable development in Romania using a principal component analysis technique (PCA) together with a multivariate decision criterion. Our analysis was conducted at the level of the 40 Romanian counties (except Ilfov county and also the capital city Bucharest) using the most relevant regional indicators for the year 2011 taken from the Tempo database of the National Institute of Statistics.

Concluding we can state that the paper provides a suitable method for choosing the counties that have the greatest probability of being development poles, based on the most important components obtained through PCA (the first five components that have Eigenvalues greater than 1 ).

Looking at the empirical results we have to mention that the number of graduates, the number of active enterprises, the number of cities, the life expectancy, the activity rate and the cultivated area are the initial variables that can be used in order to explain the phenomenon of sustainable regional development in Romania (each of them shows a significant correlation with one of the PCs). After conducting the analysis using all the possible combinations of the identified PCs (combinations of two) we have identified four classes of counties. The first class contains counties that have the greatest probability of being selected as development poles (they are displayed on charts in the first Quadrant - they perform better than the average for both components) because they appear as potential poles in six of the conducted analysis: Bihor, Cluj, Mures, Hunedoara, Constanta, Prahova, Valcea, Teleorman and Timis. The second class contains the counties that are displayed as development poles in three of the proposed combinations: Alba, Brasov, Sibiu, Suceava, Arad, Galati, Dolj, Gorj Bacau and Arges. The third class contains the counties that are displayed as development poles in only one of the conducted analyses:Satu-Mare, Neamt, Vaslui, Braila,
Buyau, Tulcea, Vrancea, Calarasi, Giurgiu, Ialomita, Mehedinti, Harghita, Botosani, Maramures, Iasi, Olt and finally, the fourth cluster contains the rest of the counties that were not identified as poles in any of the conducted analyses.

In order to improve the decision making process we suggest that the identified poles need to be further analyzed using a more geographical oriented perspective. Also, a very important direction that should be pursued by future studies must imply using other variables available at national level either obtained from the National Institute of Statistics or from other empirical studies conducted nationwide.

The importance of creating regions around strong development poles that are able to fuel a regional sustainable development in Romania is crucial today when the European model of the European Union is facing a very difficult period. Also, by creating fully functional development regions, Romania will be able to pursue its European route and reduce the obvious disparities in comparison to older EU member states. Moreover the creation of functional development regions will provide the necessary tools required by the local authorities for decreasing the disparities created at the level of living standard among different Romanian citizens.

\section{Acknowledgements}

This work was supported from the European Social Fund through Sectorial Operational Programme Human Resources Development 2007 -2013, project number POSDRU/ 159/1.5/S/142115, project title "Performance and Excellence in Postdoctoral Research in Romanian Economics Science Domain”.

\section{References}

[1] Amin, A., Thrift, N., Globalization, institutions, and regional development in Europe. Oxford University Press, Oxford, 1995.

[2] Armstrong, H. and Vickerman, R., Convergence and Divergence Among European Regions. Pion, London, 1995. 
[3] Boldea, M., Parean, M. \& Otil, M., Regional Disparity Analysis: The Case of Romania. Journal of Eastern Europe Research in Business \& Economics, 2012.

[4] Broadman, H. G. and Sun, X., The Distribution of Foreign Direct Investment in China, The World Economy, Volume 20, Issue 3, 1997,pp 339-361

[5] Cai, F., Wnag, D., Du, Y., Regional disparity and economic growth in China: The impact of labor market distortions, China Economic Review, Volume 13, Issues 2-3, 2002, pp 197-212

[6] Cantwell, J.A., Iammarino, S., 2001. EU regions and multinational corporations: change, stability and strengthening of technological comparative advantages, Industrial and Corporate Change, 10, 1007-1037.

[7] Cantwell, J.A., Piscitello, L., Recent Location of Foreign-owned Research and Development Activities by Larger Multinational Corporations in the European Regions: The Role of Spillovers and Externalities, Regional Studies, 39/1, 2005, 1-16.

[8] Chung, W. and Alcácer, J., Knowledge Seeking and Location Choice of Foreign Direct Investment in the United States, Management Science, 48/12, 2002,15341554.

[9] Crozet, M., Mayer, Th., Mucchielli, J-L., How do firms agglomerate? A study of FDI in France, Regional Science and Urban Economics, Elsevier, vol. 34(1), pp 27-54, January 2004.

[10] Dall'erba, S., Le Gallo, J., Regional convergence and the impact of European structural funds over 1989-1999: A spatial econometric analysis, Papers in Regional Science Volume 87, Issue 2, 2008, pp 219-244

[11] Danciu, A. and Strat, V. A., The FDI profile in the Romanian manufacturing sector, Review of Applied SocioEconomic Research, 4/ December 2012.

[12] Démurger, S., Infrastructure Development and Economic Growth: An Explanation for Regional Disparities in China?,
Journal of Comparative Economics, Volume 29, Issue 1, 2001, pp 95-117

[13] Fingleton, B., Estimates of Time to Economic Convergence: An Analysis of Regions of the European Union, International Regional Science Review, Volume. 22, Issue. 1, 1999, pp. 5-34

[14] Ghemawat, P. and Kennedy, R., Competitive Shocks and Industrial Structure: The Case of Polish Manufacturing., International Journal of Industrial Organization, Vol. 17, No. 6, 1999, pp. 847-867

[15] Giddings, B., Hopwood, B. and O'Brien, G., Environment, economy and society: fitting them together into sustainable development. Sustainable Development, 10, 2002, 187-196. doi: 10.1002/sd.199

[16] Goschin, Z., Constantin, D.-L., Roman, M. and Ileanu, B., The current state and dynamics of regional disparities in Romania, Romanian Journal of Regional Sciences, Vol. 2, no 2, 2008.

[17] Hopwood, B., Mellor, M. and O'Brien, G., Sustainable development: mapping different approaches. Sustainable Development, 13, 2005, 38-52.

[18] Ileanu, B. ,Isaic-Maniu, A., Herteliu, C., Intelectual capital components as causes of regional disparities. A case study in Romania., Romanian Journal of Regional Sciences, Vol. 3, no 2, 2009.

[19] Lansbury, M., N Pain, N., and Smidkova, K., Foreign direct investment in Central Europe since 1990: an econometric study, National Institute Economic Review, No. 156, 1996, pp.104-113

[20] Magrini, S., The evolution of income disparities among the regions of the European Union, Regional Science and Urban Economics Volume 29, Issue 2, pp 257-281

[21] Mariotti, S.; Piscttello, L., 1995. Information cost and location of FDIs within the host country: empirical evidence from Italy, Journal of International Business Studies, 26, 1999, 815-40.

[22] Porter, M., The Economic Performance of Regions, Regional Studies, 37/6\&7, 2003, 549-578 
[23] Przybylska, K. and Malina, A., The Determinants of Foreign Direct Investment in Transforming Economies: Empirical Evidence From Poland, Statistics in Transition 4(5), 2000, pp 883-899.

[24] Roman, M., Regional efficiency of the knowledge economy in the new EU countries: The Romanian and Bulgarian case, Romanian Journal of Regional Sciences, Vol. 4, no 1, 2010.

[25] Singh, G. K., Kogan, M. D., van Dyck, P. C.,. A Multilevel Analysis of State and Regional Disparities in Childhood and Adolescent Obesity in the United States, Journal of Community Health, Volume 33, Issue 2, 2008, pp 90-102

[26] Soukiazis, E. and Proença, S., Tourism as an alternative source of regional growth in Portugal: a panel data analysis at NUTS II and III levels, Port Econ J, Issue 7, 2008,pp 43-61

[27] Taylor, J. and Bradley, S., Unemployment in Europe: A Comparative Analysis of Regional Disparities in Germany, Italy and the UK, International review for Social Sciences, Volume 50, Issue 2, 1997, pp 221-245,

[28] Wei, Y., Liu, X., Parker, D. \& Vaidya, K., The regional distribution of Foreign Direct Investment in China, Regional Studies, 33 (9), 1999, pp. 857-867.

[29] Xue, Q., An Analysis on the Regional Differences of China Tourism, Journal of Guilin Institute of Tourism, Issue 1, 2005.

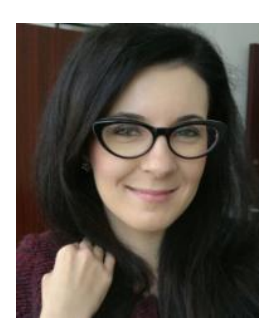

Adriana AnaMaria DAVIDESCU (ALEXANDRU) has graduated the Faculty of Cybernetics, Statistics and Economic Informatics in 2006. She holds a PhD diploma in Economics from 2011 and currently she is lecturer within the Department of Statistics and Econometrics from the Faculty of Cybernetics, Statistics and Economic Informatics and researcher within National Scientific Research Institute for Labour and Social Protection. Her main topics are analysis of informal economy, economic growth, and unemployment and also labour market studies. She is the author of more than 24 articles in international journals of which 6 in ISI journals, 15 articles published in volumes of international scientific conferences recognized in the country and abroad. She has also participated to more than 26 scientific national and international conferences and 4 summer schools. She has a reach experience in the field of applied statistics and econometrics working in different research projects of which 2 projects in quality of project manager and various as member of research team.

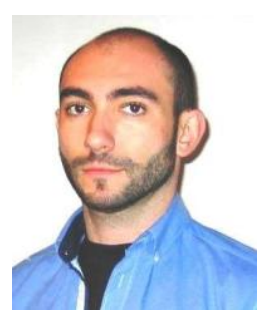

Vasile Alecsandru STRAT has graduated the Faculty of Cybernetics, Statistics and Economic Informatics in 2007. He holds a PhD diploma in Economics from 2012. He joined the Bucharest Academy of Economic Studies, in 2007 and he is currently holding the position of lecturer within the Department of Statistics and Econometrics from the Faculty of Cybernetics, Statistics and Economic Informatics. He is the author of more than 20 journal articles and articles published in volumes of international scientific conferences recognized in the country and abroad, mostly in the field of applied statistics and econometrics, foreign direct investments and higher education. He has also participated to more than 8 scientific national and international conferences and worked in 2 research projects as member of the research team. His work focuses mostly on the analysis of the foreign direct investments and higher education related aspects. 